\title{
ORAL LOSARTAN IN THE PREVENTION OF POST-ENDOSCOPIC RETROGRADE CHOLANGIOPANCREATOGRAPHY PANCREATITIS \\ By
}

YASMINE M. MASSOUD ${ }^{1^{*}}$, DOAA Z. ZAKY ${ }^{1}$, SHEREEN A. SALEH ${ }^{2^{*}}$, RAMY M. SALEM ${ }^{3}$ AND HOSSAM E. SALEM ${ }^{1}$

Departments of Tropical Medicine ${ }^{1}$, Internal Medicine ${ }^{2}$, and Clinical Pathology ${ }^{3}$, Faculty of Medicine, Ain Shams University, Cairo 11566, Egypt

( ${ }^{*}$ Correspondence:Yasminemassoud3@gmail.com;**shereen_saleh2014@hotmail.com)

\section{Abstract}

Generally speaking, acute pancreatitis is a dreadful complication of the endoscopic retro-grade cholangio-pancreatography (ERCP). But, losartan was suggested to prevent the post-ERCP acute pancreatitis. Thus, this study evaluated the use of oral losartan in prevention of the post-ERCP pancreatitis. The study was conducted on 50 patients who received $50 \mathrm{mg}$ of oral losartan one hour before ERCP (Study group), and another 50 patients who underwent ERCP without losartan prophylaxis (Control group). Serum amylase and lipase were measured before and after ERCP. The results showed that two patients of the study group and one patient of the control one developed post ERCP-pancreatitis in a total percent of 3\%. The use of oral Losartan in a dose of 50mg an hour before the ERCP did not significantly decrease the incidence of pancreatitis. The ERCP duration was significantly longer among cases that developed pancreatitis in the study group.

Key word: Egypt, Patients, Losartan, ARBs, ERCP, pancreatitis.

\section{Introduction}

Acute pancreatitis is a sudden inflammation of the pancreas characterized by the release of pancreatic digestive enzymes from damaged exocrine cells and presented clinically in the following two forms: acute and chronic (Petrov et al, 2010). In order of frequency, causes included a gallstone in the common bile duct, heavy alcohol use, systemic disease; trauma; and, in minors, mumps, or mumps, that may progress to chronic pancreatitis (Khirallah et al, 2019). Acute pancreatitis is a thoughtful problem after endoscopic retrograde cholangio-pancreatography (ERCP) touching $1 \%-10 \%$ of the patients (Tsujino et al, 2005).

Raise of pancreatic enzymes in the serum was identified as hyperenzymemia in $25 \%$ $40 \%$ of the patients after ERCP (Dong et al, 2018). Although serum pancreatic enzymes may rise temporarily in as many as $75 \%$ of patients, such rise did not essentially establish pancreatitis. The recognized hazardous factors for post-ERCP pancreatitis include female sex, previous pancreatitis, and procedure-related factors, as well as pancreatic duct injection, cannulation difficulties, and use of sphincterotomy (Masci et al, 2003).

Some medications were assessed to inhibit post-ERCP pancreatitis such as diclofenac suppositories, interleukin 10 (Deviere et al, 2001), glyceryl trinitrate and antibiotics (Freeman, 2002), or low-dose heparin (Li et al, 2012) and others.

Angiotensin type1 receptor blockers (ARB) prevented the occurrence of pancreatitis or pancreatic hyper-enzymemia after ERCP. Acute pancreatitis triggers a local pancreatic renin-angiotensin system together with the circulating renin-angiotensin system (Leung, 2007). Experimental studies showed that the angiotensin receptor and angiotensinogen were highly expressed in inflamed pancreatic tissue, and that administration of angiotensin was found to increase the secretion of pancreatic enzymes and that the increase in the secretion could be inhibited by the ARB losartan (Tsang et al, 2004). Losartan $\left(\right.$ Cozaar $\left.{ }^{\mathrm{TM}}\right)$ proved to prevent induced acute pancreatitis in patients (Bexelius et al, 2012).

The study aimed to evaluate the use of oral losartan in the prevention of post-ERCP pancreatitis patients. 


\section{Materials and Methods}

Ethics: This randomized controlled clinical trial was conducted on 100 patients of both sexes. The study was reviewed and approved by the Ethics Committee of the Faculty of Medicine, Ain Shams University with an approval number $138 / 2015$. All the procedures done in this study involved human participants were in accordance with the ethical standards of the Institutional and/or National Research Committee and with 1964 Helsinki declaration and its later amendments or comparable ethical standards. Informed written consent was obtained from all individual participants included in the study. The randomized controlled clinical trial was registered in Clinical/Trials.gov with ID: NCT04049734.

Study design: All patients were indicated for ERCP and conducted in Ain Shams Specialized Hospital during the period from January 2015 to March 2017. They were divided into 2 groups: G1: included 50 patients (31 males \& 19 females, aged between $20 \& 70$ years $(40.9 \pm 12.88)$ and received 50 mg of oral Losartan an hour before ERCP (study group). G2: Included 50 patients (29 males \& 21 females, aged between $20 \& 70$ years $(45.3 \pm 14.18)$ and underwent ERCP without Losartan prophylaxis (control group).

Inclusion criteria: Any adult patient indicated for ERCP including those with obstructive jaundice, dilated intrahepatic or extrahepatic biliary ducts due to calcular, malignant or benign pathologies was included.

Exclusion criteria: Patients refused study or signed the informed consent, or with clinIcal evident acute pancreatitis, or with previous endoscopic or surgical sphincterotomy, or on Losartan, or allergic or hypersensitive to it or hydro soluble contrast solutions, or receiving NSAIDS within a week prior to assessment, or with severe comorbid conditions as cardiovascular disease, renal failure or decompensated cirrhosis were excluded.

All patients were subjected to: 1- Full history mainly on previous ERCP, endoscopical or surgical sphincterotomy, pancreatitis, comorbid conditions, \& drug history. 2- General clinical examination. 3- Laboratory examinations including: a- complete blood picture was done using Coulter counter (Beckman. Coulter, California, USA), b- Prothrombin time and partial thromboplastin time were determined (Diagnostica Stago, Asnieres, France), and c- Biochemical examinations including: liver functions (AST, ALT, total bilirubin, direct bilirubin, gamma-glutamyl transferase \& serum albumin), renal functions (serum creatinine \& blood urea nitrogen), serum amylase and serum lipase levels before and after the procedure. All measured used the Synchron CX9 Autoanalyzer (Beckman Instruments Inc.; Scientific Instruments Division, Fullerton, CA 926343100 , USA) applying enzymatic colorimetric method.

ERCP: Patients were asked to fast for 6-8 hours before the procedure. They were monitored by pulse oximetry. Ventilatory function was monitored by observation and/or auscultation. Blood pressure and pulse were monitored at 5-minutes intervals during the procedure. Prophylactic antibiotics were not routinely given to all patients. Patients who were received prophylactic antibiotics were recorded. The procedure was done under the propofol general anesthesia. The patient put on his left side on the examining table in an $\mathrm{x}$-ray room. Introduction of the scope into the second part of the duodenum was done where the major papilla was located. The endoscopy was straightened to face papillary orifice and cannulation using the standard sphincterotome with guide wire inside was done. Opacification of the common bile duct, hepatic ducts, and intra-hepatic biliary radicals by injecting a diluted dye into the biliary tree was done. Failure of cannulation of CBD with guide wire due to edema of the papilla, anatomical deformity, or impacted stone at the lower part of CBD, necessitated precut sphincterotomy using standard sphincterotome or needle papillotome depending on the situation. The patients were followed 
up clinically for the next $24 \mathrm{hrs}$ for any abdominal pain or other complications.

Laboratory investigations including serum amylase and serum lipase were evaluated and followed up together with radiological confirmation of cases suspected to have pancreatitis. Post ERCP pancreatitis was diagnosed and evaluated (Cotton et al, 2009).

Diagnosis of procedure-related pancreatitis was based on an increased serum amylase level greater than three times the upper normal limits, and association with abdominal pain requiring analgesics and persisting for at least $24 \mathrm{hrs}$ after the procedure. Pancreatitis were graded as mild required 2-3 days hospitalization, moderate required 4-10 days $\&$ severe required more than 10 days in intensive care, or surgical intervention. If indicated, abdominal ultrasonography \& CT scan were done to evaluate the severity of the complications.

Primary outcome to find post-ERCP pancreatitis incidence in each group related to tested medication and secondary outcome to identify predisposing factor of post-ERCP pancreatitis.
Statistical analysis: Data were coded, tabulated, and analyzed by using IBM SPSS Statistics, V. 22.0 (IBM Co., Chicago, USA, 2013). Descriptive statistics were done for quantitative data as minimum and maximum of range as well as $\mathrm{M} \pm \mathrm{SD}$ for quantitative parametric data. Median and inter-quartile range used for quantitative non-parametric data. Inferential analyses were done for quantitative variants using independent $t$-test in two independent groups with parametric data and paired t-test in cases of two dependent groups with parametric data. Mann Whiteny U-test was used in cases of two independent groups with non-parametric data and Wilcoxon signed rank test in two dependent groups with non-parametric data. In qualitative data, inferential analyses for independent variables were done using Chi-square test for differences between proportions and Fisher's exact test for variables with small expected numbers. Significance level was considered at $\mathrm{P}$ value $<0.05$.

\section{Results}

The results were given in tables $(1,2,3,4$ \& 5).

Table 1: Comparison between groups regarding post ERCP complications:

\begin{tabular}{|l|c|c|c|c|}
\hline Complication & Study (50) G1 & Control (50) G2 & $\mathrm{P}_{\mathrm{S} / \mathrm{C}}$ & RR (95\% CI) \\
\hline Hyperamylasemia & $38(76 \%)$ & $16(32 \%)$ & $\# 0.00^{*}$ & $0.33(0.22-0.49)$ \\
\hline Pancreatitis & $2(4 \%)$ & $1(2 \%)$ & $\# 0.56$ & -- \\
\hline Pain & $11(22 \%)$ & $14(28 \%)$ & $\# 0.49$ & -- \\
\hline Fever & $6(12 \%)$ & $9(18 \%)$ & $\# 0.40$ & $0.81(0.40-1.64)$ \\
\hline Vomiting & $10(20 \%)$ & $15(30 \%)$ & $\# 0.25$ & $0.56(0.34-0.93)$ \\
\hline Bleeding & $2(4 \%)$ & $1(2 \%)$ & $\# 0.56$ & -- \\
\hline Infection & $3(6 \%)$ & $4(8 \%)$ & $\# 0.69$ & $1.00(0.52-1.92)$ \\
\hline Hospitalization & $5(10 \%)$ & $7(14 \%)$ & $\# 0.77$ & -- \\
\hline Death & $2(4 \%)$ & $1(2 \%)$ & $\# 0.56$ & -- \\
\hline
\end{tabular}

\#Chi square test, RR: Relative risk, CI: Confidence interval *Significant

Patients had calcular obstructive jaundice (7\%). No significant difference was between (54\%), malignant $(20 \%)$, benign stricture groups as to post ERCP pancreatitis incidence (19\%), and other as Sphincter of oddi dys-dence or others only hyperamylasemia was function and post cholecystectomy jaundice significant high in G1 than G2 (Tab. 1).

Table 2: Comparison between groups regarding serum amylase level (IU/L)

\begin{tabular}{|c|c|c|c|c|}
\hline Time & Amylase Measure & Study (50) & Control (50) & $\mathrm{P}_{\mathrm{S} / \mathrm{C}}$ \\
\hline \multirow{2}{*}{ Before } & Median(IQR) & $39.5(31.0-58.0)$ & $45.5(32.0-63.5)$ & \multirow{2}{*}{$<0.319$} \\
\hline & Range & $22.0-132.0$ & $13.0-120.0$ & \\
\hline \multirow{2}{*}{ After } & Median(IQR) & $610.5(310.0-971.3)$ & $145.0(94.5-249.5)$ & \multirow{2}{*}{$<0.001 *$} \\
\hline & Range & $61.0-1686.0$ & $32.0-2376.0$ & \\
\hline \multicolumn{2}{|r|}{$\mathrm{PB} / \mathrm{A}$} & $\&<0.001 *$ & $\&<0.001 *$ & $<0.001 *$ \\
\hline
\end{tabular}


Table 3: Comparison between groups regarding serum lipase level (IU/L):

\begin{tabular}{|c|c|c|c|c|}
\hline Time & Lipase Measure & Study (50) & Control (50) & $\mathrm{P}_{\mathrm{S} / \mathrm{C}}$ \\
\hline \multirow{2}{*}{ Before } & Median (IQR) & $41.5(32.0-54.5)$ & $38.5(27.8-67.0)$ & \multirow{2}{*}{$<0.885$} \\
\hline & Range & $13.0-352.0$ & $16.0-129.0$ & \\
\hline \multirow{2}{*}{ After } & Median (IQR) & $215.5(107.3-521.3)$ & $96.0(63.8-295.5)$ & \multirow{2}{*}{$<0.002 *$} \\
\hline & Range & $43.0-2215.0$ & $22.0-2197.0$ & \\
\hline \multicolumn{2}{|r|}{$\mathrm{PB} / \mathrm{A}$} & $\&<0.001 *$ & $\&<0.001 *$ & $<0.001 *$ \\
\hline
\end{tabular}

*Significant

Serum \& lipase levels were significantly high in G1 than in G2 after ERCP (Tabs, 2, \&3).

Table 4: Comparison between cases with and without pancreatitis:

\begin{tabular}{|c|c|c|c|c|c|}
\hline \multicolumn{3}{|l|}{ Variable } & Pancreatitis $(\mathrm{n}=2)$ & Non $(n=48)$ & $\mathrm{P}_{\mathrm{S} / \mathrm{C}}$ \\
\hline Age & \multicolumn{2}{|l|}{$\mathrm{M} \pm \mathrm{SD}$} & $44.5 \pm 21.92$ & $40.5 \pm 12.74$ & $<0.67$ \\
\hline \multirow{2}{*}{ Sex } & \multicolumn{2}{|l|}{ Male } & $1(50 \%)$ & $30(62.5 \%)$ & \multirow{2}{*}{$<0.72$} \\
\hline & \multicolumn{2}{|l|}{ Female } & $1(50 \%)$ & $18(37.5 \%)$ & \\
\hline \multirow{4}{*}{ Diagnosis } & \multicolumn{2}{|l|}{ Calcular OJ } & $0(0 \%)$ & $26(55.10 \%)$ & \multirow{4}{*}{$<0.12$} \\
\hline & \multicolumn{2}{|l|}{ Benign stricture } & $2(100 \%)$ & $11(22.92 \%)$ & \\
\hline & \multicolumn{2}{|l|}{ Malignant OJ } & $0(0 \%)$ & $8(16.67 \%)$ & \\
\hline & \multicolumn{2}{|l|}{ Others } & $0(0 \%)$ & $3(8.16 \%)$ & \\
\hline \multicolumn{3}{|c|}{ Prophylactic antibiotics. } & $1(50.0 \%)$ & $8(16.67 \%)$ & $<0.23$ \\
\hline \multicolumn{3}{|c|}{ Precut needle sphincterotomy. } & $2(100 \%)$ & $21(43.7 \%)$ & $<0.12$ \\
\hline \multicolumn{3}{|c|}{ Use of Dormia basket. } & $0(0 \%)$ & $2(4.17 \%)$ & $<0.77$ \\
\hline \multicolumn{3}{|c|}{ Use of dilatation balloon. } & $1(50 \%)$ & $29(60.4 \%)$ & $<0.77$ \\
\hline \multicolumn{3}{|c|}{ Use of sohindra dilator. } & $0(0 \%)$ & $2(4.17 \%)$ & $<0.77$ \\
\hline \multicolumn{3}{|c|}{ Use of internal lithotripser. } & $0(0.0 \%)$ & $2(4.17 \%)$ & $<0.77$ \\
\hline \multicolumn{3}{|c|}{ Stenting of CBD by plastic stent. } & $1(50 \%)$ & $27(56.25 \%)$ & $<0.86$ \\
\hline \multirow{2}{*}{\multicolumn{2}{|c|}{$\begin{array}{l}\text { Unintended cannulation of } \\
\text { pancreatic duct }\end{array}$}} & Negative & $0(0 \%)$ & $26(54.17 \%)$ & \multirow{2}{*}{$<0.20$} \\
\hline & & Positive & $2(100 \%)$ & $22(45.83 \%)$ & \\
\hline \multirow{2}{*}{\multicolumn{2}{|c|}{ Precut needle sphincterotomy }} & Negative & $1(50 \%)$ & $11(22.92 \%)$ & \multirow[t]{2}{*}{$<0.38$} \\
\hline & & Positive & $1(50 \%)$ & $37(77.08 \%)$ & \\
\hline \multirow{2}{*}{\multicolumn{2}{|c|}{ Bleeding during procedure }} & Negative & $2(100 \%)$ & $41(85.42 \%)$ & \multirow{2}{*}{$<0.56$} \\
\hline & & Positive & $0(0 \%)$ & $7(14.58 \%)$ & \\
\hline \multicolumn{2}{|c|}{ Duration of ERCP (minutes) } & $\mathrm{M} \pm \mathrm{SD}$ & $72.5 \pm 24.75$ & $45.02 \pm 10.86$ & $<0.00^{*}$ \\
\hline
\end{tabular}

Two patients (G1) \& 1 patient (G2) developed duration was significantly longer among post-ERCPpancreatitis (3\%). ERCP cases developed pancreatitis in G1 (Tab. 4).

Table 5: Comparison between cases with and without pancreatitis control group:

\begin{tabular}{|c|c|c|c|c|c|}
\hline \multicolumn{3}{|l|}{ Variable } & Pancreatitis $(n=1)$ & Non $(n=49)$ & $\mathrm{P}_{\mathrm{S} / \mathrm{C}}$ \\
\hline Age & \multicolumn{2}{|l|}{$\mathrm{M} \pm \mathrm{SD}$} & 42 & $45.41 \pm 14.96$ & $<0.82$ \\
\hline \multirow{2}{*}{ Sex } & \multicolumn{2}{|l|}{ Male } & $1(100 \%)$ & $28(57.14 \%)$ & \multirow{2}{*}{$<0.39$} \\
\hline & \multicolumn{2}{|l|}{ Female } & $0(0 \%)$ & $21(42.86 \%)$ & \\
\hline \multirow{4}{*}{ Diagnosis } & \multicolumn{2}{|l|}{ Calcular OJ } & $1(100 \%)$ & $27(55.10 \%)$ & \multirow{4}{*}{$<0.85$} \\
\hline & \multicolumn{2}{|l|}{ Benign stricture } & $0(0.0 \%)$ & $6(12.24 \%)$ & \\
\hline & \multicolumn{2}{|l|}{ Malignant OJ } & $0(0 \%)$ & $12(24.49 \%)$ & \\
\hline & \multicolumn{2}{|l|}{ Others } & $0(0.0 \%)$ & $4(8.16 \%)$ & \\
\hline \multicolumn{3}{|c|}{ Prophylactic antibiotics. } & $1(100.0 \%)$ & $5(10.2 \%)$ & $<0.01 *$ \\
\hline \multicolumn{3}{|c|}{ Precut needle sphincterotomy. } & $0(0 \%)$ & $18(36.7 \%)$ & $<0.45$ \\
\hline \multicolumn{3}{|c|}{ Use of Dormia basket. } & $0(0 \%)$ & $1(2.04 \%)$ & $<0.89$ \\
\hline \multicolumn{3}{|c|}{ Use of dilatation balloon. } & $1(100 \%)$ & $21(42.8 \%)$ & $<0.25$ \\
\hline \multicolumn{3}{|c|}{ Use of sohindra dilator. } & $0(0 \%)$ & $3(6.12 \%)$ & $<0.79$ \\
\hline \multicolumn{3}{|c|}{ Use of internal lithotripser. } & $0(0.0 \%)$ & $0(0 \%)$ & $<1.00$ \\
\hline \multicolumn{3}{|c|}{ Stenting of CBD by plastic stent. } & $1(100 \%)$ & $28(57.14 \%)$ & $<0.39$ \\
\hline \multirow{2}{*}{\multicolumn{2}{|c|}{$\begin{array}{l}\text { Unintended cannulation of } \\
\text { pancreatic duct }\end{array}$}} & Negative & $0(0 \%)$ & $26(53 \%)$ & \multirow{2}{*}{$<0.29$} \\
\hline & & Positive & $1(100 \%)$ & $23(47 \%)$ & \\
\hline \multirow{2}{*}{\multicolumn{2}{|c|}{ Precut needle sphincterotomy }} & Negative & $1(100 \%)$ & $36(73.47 \%)$ & \multirow[t]{2}{*}{$<0.55$} \\
\hline & & Positive & $0(0 \%)$ & $13(26.53 \%)$ & \\
\hline \multirow{2}{*}{\multicolumn{2}{|c|}{ Bleeding during procedure }} & Negative & $1(100 \%)$ & $1(2.04 \%)$ & \multirow[b]{2}{*}{$<0.89$} \\
\hline & & Positive & $0(0 \%)$ & $48(97.96 \%)$ & \\
\hline \multicolumn{2}{|c|}{ ERCP duration of (minutes) } & $\mathrm{M} \pm \mathrm{SD}$ & $55 \pm 0.00$ & $38.84 \pm 9.44$ & $<0.09$ \\
\hline
\end{tabular}

Prophylactic antibiotic used was significantly more frequent among G1 than G2 (Tab. 5). 


\section{Discussion}

Endoscopists have long fought to prevent the most feared problem of ERCP, pancreatitis. The acute pancreatitis incidence after ERCP was 2-8\% depended on the indication, the patient criteria and the kind of intervention (Freeman and Guda, 2005). Outcome was $1-2 \%$ for diagnostic ERCP, 1 $4 \%$ for endoscopic sphincterotomy, $4-8 \%$ for pancreatic sphincterotomy, and $8-11 \%$ for sphincterotomy in those with sphincter of Oddi dysfunction (Rabenstein and Hahn, 2002). The incidence of post ERCP pancreatitis in the current study was 3\%, which agreed with a meta-analysis of 21 prospective cases in which incidence was approximately $3.5 \%$ but ranged widely between $1.6 \% \& 15.7 \%$ depended on patient selection (Barthet et al, 2002; Rabenstein et al, 2000; Christensen et al, 2004). Many factors were found to be associated with PEP. Some were related to the patient as age, sex, previous history of PEP. Others are related to the procedure as doing pancreatic sphincterotomy, precut sphincterotomy; whereas others are related to endoscopist experience. The risk factors can be synergistic (Funatsu et al, 2017).

In the present study, duration of the ERCP procedure was significantly longer in patients who developed pancreatitis in the study group. The use of oral losartan in the dose of $50 \mathrm{mg}$ one hour before the ERCP did not decrease the incidence of pancreatitis which was insignificant between the study and control groups. Two of the fifty patients who received losartan prophylaxis complained of pancreatitis compared with one case of pancreatitis out of the 50 cases who did not receive Losartan.

Experimental and clinical data suggested that angiotensin receptor blockers (ARBs) protected against acute pancreatitis (Dickstein et al, 1993). This was not supported by the results of the present study. This may be related to the tested dose (50mg) of Losartan which might be low to have any preventive effect, although this dose decreased the blo- od pressure in the present patients. Also, the timing of the Losartan may be the cause. Earlier administration of losartan could have been more beneficial, since a peak plasma concentration was obtained 4-6hr after an oral dose. The dose was predefined, but was chosen based on an experimental report of a protective effect on cerulein induced acute pancreatitis using $0.2 \mathrm{mg} / \mathrm{kg}$ in rats (Tsang et al, 2004).

In the present study, asymptomatic hyperamylesemia was seen in 54 patients underwent ERCP (54\% of all patients). $32 \%$ of control group developed asymptomatic hyperamylasemia, while $76 \%$ of study group who received Losartan developed asymptomatic hyperamylasemia with significant difference. Losartan did not significantly protect against the post ERCP asymptomatic hyperamylasemia. In a previous study, hyperenzymemia was reported in $24 \% \& 18 \%$ of the patients in Losartan group and in placebo group, respectively of total 76 patients. The multivariable regression model did not reveal a decreased risk of hyperenzymemia in the Losartan group as compared to the placebo group as mild acute pancreatitis occurred in $13 \%$ patients in the Losartan group and $11 \%$ patients in the placebo group without severe acute pancreatitis cases (Bexelius et al, 2012).

In the present study, the duration of ERCP procedure was significantly longer in patients who developed pancreatitis in the study group. Difficult cannulation and longer duration of the procedure was found to be an independent risk factor for pancreatitis and occurred without any apparent pancreatic duct instrumentation (Vandervoort et al, 2002). This suggested that trauma to the papilla and pancreatic sphincter with impaired pancreatic drainage may be important in the pathogenesis of pancreatitis (Ito et al, 2007).

In the present study, ages were not a significant risk factor for pancreatitis. Younger age was a significant risk factor for the pancreatitis by using the multivariate analysis (Cheng et al, 2006). The progressive decline 
in pancreatic exocrine function with aging may protect older patients from pancreatic injury.

In the present study, the sex of patients was not a significant risk factor for development of the post ERCP pancreatitis. This agreed with Ito et al. (2007) and Testoni et al. (2010). But, Christoforidis et al. (2002) and Omar et al. (2015) found that female sex was a significant risk factor due to the higher incidence of SOD, which was an independent risk factor for pancreatitis.

In the present study, unintended pancreatic duct cannulations were risk factors for pancreatitis as all pancreatitis patients had multiple unintended pancreatic duct cannulation, but without statistical difference between patients who developed pancreatitis and those who did not. This finding agreed with Freeman et al. (2001); Cheng et al. (2006) and Wang et al. (2009). The occurrence and duration of pain and the amplitude of serum amylase after ERCP were critical to differentiate the post-ERCP pancreatitis and the incidence of post-ERCP pancreatitis by using the most widely used criteria ranged from 1.9 to $11.7 \%$ depended on the adopted criteria (Testoni, 2002).

In the present study, biliary orifice balloon dilatation was associated with increased risk for post-ERCP pancreatitis $(66.6 \%$ of patients with pancreatitis underwent biliary orifice balloon dilatation), but without significant difference. Balloon dilation of the biliary sphincter to extract bile duct stone was an independent risk factor for pancreatitis in a large multicenter study with a fourfold increase in risk (Freeman et al, 2001; Cheng et al, 2006).

In the present study, precut needle sphincterotomy was associated with increased pancreatitis risk in 2 patients $(67 \%)$ that underwent precut needle spincterotomy during ERCP developed post ERCP pancreatitis. This agreed with Vandervoort et al. (2002) and Testoni et al. (2010), the later authors added that the precut needle use was a significant risk factor for pancreatitis.

\section{Conclusion}

The usage of Losartan oral 50mg before ERCP did not prevent development of post ERCP pancreatitis. Longer ERCP duration, precut needle sphincterotomy, unintended pancreatic duct cannulation and papillary balloon dilatation were found to be risk factors for development of the post ERCP pancreatitis.

\section{Acknowledgments}

The authors would like to thank all the Staff Members of the ERCP Unit, Ain Shams University Hospitals, Cairo, for allowing and facilitating the clinical study.

Conflict of interest: The authors declared that they neither have conflict of interest nor received any funds.

\section{References}

Barthet, M, Lesavre, N, Desjeux, A, Gasmi, M, Berthezene, P, et al, 2002: Complications of endoscopic sphincterotomy: results from a single tertiary referral center. Endoscopy 34:991-7.

Bexelius, TS, Blomberg, J, Lu, YX, Håkansson, HO, Möller, P, et al, 2012: Losartan to prevent hyperenzymemia after endoscopic retrograde cholangiopan-creatography: A randomized clinical trial. Wld. J. Gastrointest. Endosc. 4, 11: 506-12.

Cheng, C, Sherman, S, Watkins, J, Barnett, J, Freeman, M, et al, 2006: Risk factors for post ERCP pancreatitis: A prospective multicenter study. Am. J. Gastroenterol. 101:139-47.

Cheng, C, Sherman, S, Watkins, J, Fennerty, MB, Lee, JG, et al, 2006: Risk factors for post ERCP pancreatitis: a prospective multicenter study. Am. J. Gastroenterol. 101:139-47.

Christensen, M, Matzen, P, Schulze, S, Rosenberg, J, 2004: ERCP complications: A prospective study. Gastrointest. Endosc. 60, 5:72131.

Christoforidis, E, Goulimaris, I, Kanellos, I, Tsalis, K, Demetriades, C, et al, 2002: Post ERCP pancreatitis and hyperamylasemia: Patient-related and operative risk factors. Endoscopy 34:286-92.

Cotton, PB, Garrow, DA, Gallagher, J, Romagnuolo, J, 2009: Risk factors for complications after ERCP: a multivariate analysis of 11, 497 procedures over 12 years. Gastrointest. Endosc. 70, 1:80-8.

Deviere, J, Le Moine, O, Van Laethem, J, Eis- 
endrath, P, Ghilain, A, et al, 2001: Interleukin 10 reduces the incidence of pancreatitis after therapeutic endoscopic retrograde cholangio-pancreatography. Gastroenterology 120:498-505.

Dickstein, K, Gottlieb, S, Fleck, E, Kostis, J, Levine, TB, et al, 1993: Hemodynamic and neurohumoral effects of the angiotensin II antagonist losartan in patients with heart failure. Circulation 12:1602-9.

Dong, B, Yuan, S, Hu, J, Yan, Y, 2018: Effects of Ginkgo leaf tablets on the pharmacokinetics of losartan and its metabolite EXP3174 in rats and its mechanism. Pharm Biol. 56, 1:333-6.

Freeman, M, 2002: Adverse outcomes of the ERCP. Gastrointest. Endosc. 56, 6:273-82.

Freeman, M, DiSario, J, Nelson, D, Fennerty, MB, Lee, JG, et al, 2001: Risk factors for post ERCP pancreatitis: a prospective, multicenter study. Gastrointest. Endosc. 54:425-34.

Freeman, M, Guda, N, 2005: ERCP cannulation: A review of reported techniques. Gastrointest. Endosc. 61:112-25.

Funatsu, E, Masuda, A, Takenaka, M, Nakagawa, T, Shiom, H, et al, 2017: History of post endoscopic retrograde cholangiopancreatography pancreatitis and acute pancreatitis as risk factors for post-ERCP pancreatitis. Kobe J. Med. Sci. 63, 1:E1-8.

Ito, K, Fujita, N, Noda, Y, Kobayashi, G, Horaguchi, J, et al, 2007: Relationship between post-ERCP pancreatitis and the change of serum amylase level after the procedure. Wld. J. Gastroenterol. 13, 28:3855-60.

Khirallah, MG, Salama, FH, Arafa, MA, Eldessoki, NE, Elshanshory, M, 2019: Analysis of risk factors of pancreatic injury during elective laparoscopic splenectomy in children. J. Indian Assoc. Pediatr. Surg. 24, 3:180-4

Laugier, R, Bernard, J, Berthezen, P, Dupuy, $P$, 1901: Changes in pancreatic exocrine secretion with age: pancreatic exocrine secretion does decrease in the elderly. Digestion 50:202-11.

Leung, PS, 2007: The physiology of a local renin-angiotensin system in the pancreas. J. Physiol. 580:31-7.

Li, S, Cao, G, Chen, X, Wu, T, 2012: Low-dose heparin in the prevention of post endoscopic retrograde cholangiopancreatoraphy pancreatitis: a systematic review and meta-analysis. Eur. J. Gastroenterol. Hepatol. 24, 5:477-81

Masci, E, Cavallini, G, Mariani, A, Frulloni, L, Testoni, PA, et al, 2003: Comparison of two dosing regimens of gabexate in the prophylaxis of post- ERCP pancreatitis. Am. J. Gastroenterol. 98:2182-6.

Omar MA, Ahmed AE, Said OA, El-Amin H, 2015: Risk factors for post-ERCP pancreatitis: a prospective multicenter study in upper Egypt. Egypt. J. Surg. 34, 1:1-10.

Petrov, MS, Shanbhag, S, Chakraborty, M., Phillips, ARJ, Windsor, JA, 2010: Organ failure and infection of pancreatic necrosis as determinants of mortality in patients with acute pancreatitis. Gastroenterol. 139, 3:813-20.

Rabenstein, T, Hahn, E, 2002: Post-ERCP pancreatitis: New momentum. Endosc. 34:325-9. Rabenstein, T, Schneider, H, Bulling, D, Nicklas, M, Katalinic, A, et al, 2000: Analysis of the risk factors associated with endoscopic sphincterotomy techniques: preliminary results of a prospective study, with emphasis on the reduced risk of acute pancreatitis with low-dose anticoagulation treatment. Endoscopy 32:10-9.

Testoni, P, Mariani, A, Giussani, A, Vailati, C, Masci, E, et al, 2010: Risk Factors for postERCP pancreatitis in high- and low-volume centers and among expert and non-expert operators: A prospective multicenter Study. Am. J. Gastroenterol. 105:1753-61.

Testoni, PA, 2002: Why the incidence of post ERCP pancreatitis varies considerably? factors affecting the diagnosis and the incidence of this complication. JOP 3, 6:195-201.

Tsang, SW, Cheng, CH, Leung, PS, 2004: The role of the pancreaticrenin-angiotensin system in acinar digestive enzyme secretion and in acute pancreatitis. Regul. Pept. 119:213-9

Tsang, SW, Ip, SP, Leung, PS, 2004: Prophylactic and therapeutic treatments with AT 1 and AT 2 receptor antagonists and their effects on changes in the severity of pancreatitis. Int. J. Biochem. Cell Biol. 36, 2\330-9.

Tsujino, T, Komatsu, Y, Isayama, H, Hirano, K, Sasahira, N, et al, 2005: Ulinastatin for pancreastitis after endoscopic retrograde cholangiopancreatography: A randomized, controlled trial. Clin. Gastroenterol. Hepatol. 3, 4:376-83.

Vandervoort, J, Soetikno, R, Tham, T, Wong, RC, Ferrari, et al, 2002: Risk factors for complications after performance of ERCP. Gastrointest. Endosc. 56:652-6.

Wang, P, Li, Z, Liu, F, Ren, X, Lu, NH, et al, 2009: Risk factors for ERCP-related complications: A prospective multicenter study. Am. J. Gastroenterol. 104, 1:31-40 